\title{
STRONG CONVERGENCE THEOREMS FOR ASYMPTOTICALLY NONEXPANSIVE MAPPINGS AND ASYMPTOTICALLY NONEXPANSIVE SEMIGROUPS
}

\author{
YONGFU SU AND XIAOLONG QIN
}

Received 22 April 2006; Accepted 14 July 2006

Strong convergence theorems are obtained from modified Halpern iterative scheme for asymptotically nonexpansive mappings and asymptotically nonexpansive semigroups, respectively. Our results extend and improve the recent ones announced by Nakajo, Takahashi, Kim, Xu, and some others.

Copyright (c) 2006 Y. Su and X. Qin. This is an open access article distributed under the Creative Commons Attribution License, which permits unrestricted use, distribution, and reproduction in any medium, provided the original work is properly cited.

\section{Introduction and preliminary}

Let $H$ be a real Hilbert space, $C$ a nonempty closed convex subset of $H$, and $T: C \rightarrow C$ a mapping. Recall that $T$ is nonexpansive if

$$
\|T x-T y\| \leq\|x-y\| \quad \forall x, y \in C,
$$

and $T$ is asymptotically nonexpansive if there exists a sequence $\left\{k_{n}\right\}$ of positive real numbers with $\lim _{n \rightarrow \infty} k_{n}=1$ and such that

$$
\left\|T^{n} x-T^{n} y\right\| \leq k_{n}\|x-y\| \quad \forall n \geq 1, x, y \in C
$$

A point $x \in C$ is a fixed point of $T$ provided $T x=x$. Denote by $F(T)$ the set of fixed points of $T$; that is, $F(T)=\{x \in C: T x=x\}$. Also, recall that a family $S=\{T(s) \mid 0 \leq s<\infty\}$ of mappings from $C$ into itself is called an asymptotically nonexpansive semigroup on $C$ if it satisfies the following conditions:

(i) $T(0) x=x$ for all $x \in C$;

(ii) $T(s+t)=T(s) T(t)$ for all $s, t \geq 0$;

(iii) there exists a positive valued function $L:[0, \infty) \rightarrow[1, \infty)$ such that $\lim _{s \rightarrow \infty} L_{s}=1$ and $\|T(s) x-T(s) y\| \leq L_{s}\|x-y\|$ for all $x, y \in C$ and $s \geq 0$;

(iv) for all $x \in C, s \mapsto T(s) x$ is continuous. 
We denote by $F(S)$ the set of all common fixed points of $S$, that is, $F(S)=\bigcap_{0 \leq s<\infty}$ $F(T(s))$. It is known that $F(S)$ is closed and convex. Construction of fixed point of nonexpansive mapping is an important subject in the theory of nonexpansive mappings and finds applications in a number of applied areas, in particular, in image recovery and signal processing (see, e.g., $[14,15]$ ). However, the sequence $\left\{T^{n} x\right\}_{n=0}^{\infty}$ of iterates of the mapping $T$ at a point $x \in C$ may not converge in the weak topology. Thus averaged iterations prevail. In fact, Mann's iterations do have weak convergence. More precisely, Mann's iteration procedure is a sequence $\left\{x_{n}\right\}$ defined by

$$
x_{n+1}=\alpha_{n} x_{n}+\left(1-\alpha_{n}\right) T x_{n},
$$

where the initial guess $x_{0} \in C$ is chosen arbitrarily.

Reich [9] proved that if $E$ is a uniformly convex Banach space with a Fréchet differentiable norm and if $\left\{\alpha_{n}\right\}$ is chosen such that $\sum_{n=1}^{\infty} \alpha_{n}\left(1-\alpha_{n}\right)=\infty$, then the sequence $\left\{x_{n}\right\}$ defined by (1.3) converges weakly to a fixed point of $T$. However we note that Mann's iterations have only weak convergence even in a Hilbert space [1].

Recently many authors want to modify the Mann iteration method (1.3) so that strong convergence is guaranteed have recently been made. Nakajo and Takahashi [8] proposed the following modification of the Mann iteration (1.3) for a single nonexpansive mapping $T$ in a Hilbert space:

$$
\begin{gathered}
x_{0} \in C \quad \text { arbitrarily, } \\
y_{n}=\alpha_{n} x_{n}+\left(1-\alpha_{n}\right) T x_{n}, \\
C_{n}=\left\{z \in C:\left\|y_{n}-z\right\| \leq\left\|x_{n}-z\right\|\right\}, \\
Q_{n}=\left\{z \in C:\left\langle x_{0}-x_{n}, x_{n}-z\right\rangle \geq 0\right\}, \\
x_{n+1}=P_{C_{n} \cap Q_{n}} x_{0},
\end{gathered}
$$

where $P_{K}$ denotes the metric projection from $H$ onto a closed convex subset $K$ of $H$ and proved that sequence $\left\{x_{n}\right\}$ converges strongly to $P_{F(T)} x_{0}$.

They also proposed the following iteration process for a nonexpansive semigroup $S=$ $\{T(s) \mid 0 \leq s<\infty\}$ in a Hilbert space $H$ :

$$
\begin{gathered}
x_{0} \in C \quad \text { arbitrarily, } \\
y_{n}=\alpha_{n} x_{n}+\left(1-\alpha_{n}\right) \frac{1}{t_{n}} \int_{0}^{t_{n}} T(s) x_{n} d s, \\
C_{n}=\left\{z \in C:\left\|y_{n}-z\right\| \leq\left\|x_{n}-z\right\|\right\}, \\
Q_{n}=\left\{z \in C:\left\langle x_{0}-x_{n}, x_{n}-z\right\rangle \geq 0\right\}, \\
x_{n+1}=P_{C_{n} \cap Q_{n}} x_{0} .
\end{gathered}
$$

They proved that if the sequence $\left\{\alpha_{n}\right\}$ is bounded from one and if $\left\{t_{n}\right\}$ is a positive real divergent sequence, then the sequence $\left\{x_{n}\right\}$ generated by (1.5) converges strongly to $P_{F(S)} x_{0}$. 
Halpern [3] firstly studied iteration scheme as follows:

$$
x_{n+1}=\alpha_{n} u+\left(1-\alpha_{n}\right) T x_{n}, \quad n \geq 0,
$$

where $u, x_{0} \in C$ are arbitrary (but fixed) and $\left\{\alpha_{n}\right\} \subset(0,1)$. He pointed out that the conditions $\lim _{n \rightarrow \infty} \alpha_{n}=0$ and $\sum_{n=1}^{\infty} \alpha_{n}=\infty$ are necessary in the sense that if the iteration scheme (1.6) converges to a fixed point of $T$, then these conditions must be satisfied. Ten years later, Lions [6] investigated the general case in Hilbert space under the conditions

$$
\lim _{n \rightarrow \infty} \alpha_{n}=0, \quad \sum_{n=1}^{\infty} \alpha_{n}=\infty, \quad \lim _{n \rightarrow \infty} \frac{\alpha_{n}-\alpha_{n+1}}{\alpha_{n+1}^{2}}=0
$$

on the parameters. However, Lions' conditions on the parameters were more restrictive and did not include the natural candidate $\left\{\alpha_{n}=1 / n\right\}$. Reich [10] gave the iteration scheme (1.6) in the case when $E$ is uniformly smooth and $\alpha_{n}=n^{-\delta}$ with $0<\delta<1$.

Wittmann [13] studied the iteration scheme (1.6) in the case when $E$ is a Hilbert space and $\left\{\alpha_{n}\right\}$ satisfies

$$
\lim _{n \rightarrow \infty} \alpha_{n}=0, \quad \sum_{n=1}^{\infty} \alpha_{n}=\infty, \quad \sum_{n=1}^{\infty}|| \alpha_{n+1}-\alpha_{n} \|<\infty .
$$

Reich [11] obtained a strong convergence of the iterates (1.6) with two necessary and decreasing conditions on parameters for convergence in the case when $E$ is uniformly smooth with a weakly continuous duality mapping.

Recently, Martinez-Yanes and $\mathrm{Xu}$ [7] adapted the iteration (1.6) in Hilbert space as follows:

$$
\begin{gathered}
x_{0} \in C \quad \text { arbitrarily, } \\
y_{n}=\alpha_{n} x_{0}+\left(1-\alpha_{n}\right) T x_{n}, \\
C_{n}=\left\{z \in C:\left\|y_{n}-z\right\|^{2} \leq\left\|x_{n}-z\right\|^{2}+\alpha_{n}\left(\left\|x_{0}\right\|^{2}+2\left\langle x_{n}-x_{0}, z\right\rangle\right)\right\}, \\
Q_{n}=\left\{z \in C:\left\langle x_{0}-x_{n}, x_{n}-z\right\rangle \geq 0\right\}, \\
x_{n+1}=P_{C_{n} \cap Q_{n}} x_{0} .
\end{gathered}
$$

More precisely, they prove the following theorem.

Theorem 1.1 (Martinez-Yanes and Xu [7]). Let $H$ be a real Hilbert space, $C$ a closed convex subset of $H$, and $T: C \rightarrow C$ a nonexpansive mapping such that $F(T) \neq \varnothing$. Assume that $\left\{\alpha_{n}\right\} \subset(0,1)$ is such that $\lim _{n \rightarrow \infty} \alpha_{n}=0$. Then the sequence $\left\{x_{n}\right\}$ defined by (1.9) converges strongly to $P_{F(T)} x_{0}$.

The purpose of this paper is to employ Nakajo and Takahashi's [8] idea to modify process (1.6) for asymptotically nonexpansive mappings and asymptotically nonexpansive semigroup to have strong convergence theorem in Hilbert space.

In the sequel, we need the following lemmas for the proof of our main results. 
Lemma 1.2. Let $K$ be a closed convex subset of real Hilbert space $H$ and let $P_{K}$ be the metric projection from $H$ onto $K$ (i.e., for $x \in H, P_{k}$ is the only point in $K$ such that $\left\|x-P_{k} x\right\|=$ $\inf \{\|x-z\|: z \in K\})$. Given $x \in H$ and $z \in K$. Then $z=P_{K} x$ if and only if there holds the relations

$$
\langle x-z, y-z\rangle \leq 0 \quad \forall y \in K
$$

Lemma 1.3 (Lin et al. [5]). Let $T$ be an asymptotically nonexpansive mapping defined on a bounded closed convex subset $C$ of a Hilbert space $H$. Assume that $\left\{x_{n}\right\}$ is a sequence in $C$ with the properties (i) $x_{n} \rightarrow p$ and (ii) $T x_{n}-x_{n} \rightarrow 0$. Then $p \in F(T)$.

Lemma 1.4 (Kim and $\mathrm{Xu}[4]$ ). Let $C$ be a nonexpansive bounded closed convex subset of $H$ and let $S=\{T(t): 0 \leq t<\infty\}$ be an asymptotically nonexpansive semigroup on $C$. Then it holds that

$$
\limsup _{s \rightarrow \infty} \limsup _{n \rightarrow \infty} \sup _{x \in C}\left\|T(s)\left(\frac{1}{t} \int_{0}^{t} T(u) x_{n} d u\right)-\frac{1}{t} \int_{0}^{t} T(u) x_{n} d u\right\|=0 .
$$

Lemma 1.5. Let $C$ be a nonexpansive bounded closed convex subset of $H$ and let $S=\{T(s)$ : $0 \leq s<\infty\}$ be an asymptotically nonexpansive semigroup on $C$. If $\left\{x_{n}\right\}$ is a sequence in $C$ satisfying the properties (i) $x_{n} \rightarrow z$; (ii) $\limsup _{s \rightarrow \infty} \limsup _{n \rightarrow \infty}\left\|T(s) x_{n}-x_{n}\right\|=0$, then $z \in F(S)$.

Proof. This lemma is the continuous version of [12, Lemma 2.3]. The proof given in [12] is easily extended to the continuous case.

\section{Main results}

In this section we propose a modification of the Halpern iteration method to have strong convergence for asymptotically nonexpansive mappings and asymptotically nonexpansive semigroup in Hilbert space.

Theorem 2.1. Let $C$ be a bounded closed convex subset of a Hilbert space $H$ and let $T: C \rightarrow$ $C$ be an asymptotically nonexpansive mapping with sequence $\left\{k_{n}\right\}$. Assume that $\left\{\alpha_{n}\right\}_{n=0}^{\infty}$ and $\left\{\beta_{n}\right\}_{n=0}^{\infty}$ are sequences in $(0,1)$ such that $\lim _{n \rightarrow \infty} \alpha_{n}=0, \lim _{n \rightarrow \infty} \beta_{n}=1$, and $M$ is an appropriate constant such that $M \geq\left\|x_{0}-v\right\|^{2}$, for all $v \in C$. Define a sequence $\left\{x_{n}\right\}$ in $C$ by the following algorithm:

$$
\begin{gathered}
x_{0} \in C \quad \text { chosen arbitrarily, } \\
z_{n}=\beta_{n} x_{n}+\left(1-\beta_{n}\right) T^{n} x_{n}, \\
y_{n}=\alpha_{n} x_{0}+\left(1-\alpha_{n}\right) T^{n} z_{n}, \\
C_{n}=\left\{v \in C:\left\|y_{n}-v\right\|^{2} \leq\left\|x_{n}-v\right\|^{2}+\left\|z_{n}\right\|^{2}-\left\|x_{n}\right\|^{2}+2\left\langle x_{n}-z_{n}, v\right\rangle+\alpha_{n} M\right\}, \\
Q_{n}=\left\{v \in C:\left\langle x_{0}-x_{n}, x_{n}-v\right\rangle \geq 0\right\}, \\
x_{n+1}=P_{C_{n} \cap Q_{n}} x_{0} .
\end{gathered}
$$

Then $\left\{x_{n}\right\}$ converges to $P_{F(T)} x_{0}$, provided $k_{n}^{2}\left(1-\alpha_{n}\right)-1 \leq 0$. 
Proof. From [2] we know that $T$ has a fixed point in $C$. That is, $F(T) \neq \varnothing$. It is obviously that $C_{n}$ is closed and $Q_{n}$ is closed and convex for each $n \geq 0$. Next observe that $C$ is convex. For $v_{1}, v_{2} \in C_{n}$ and $t \in(0,1)$, putting $v=t v_{1}+(1-t) v_{2}$. It is sufficient to show that $v \in C_{n}$. Indeed, the defining inequality in $C_{n}$ is equivalent to the inequality

$$
2\left\langle z_{n}-y_{n}, v\right\rangle \leq\left\|z_{n}\right\|^{2}-\left\|y_{n}\right\|^{2}+\alpha_{n} M
$$

Therefore, we have

$$
\begin{aligned}
2\left\langle z_{n}-y_{n}, v\right\rangle & =2\left\langle z_{n}-y_{n}, t v_{1}+(1-t) v_{2}\right\rangle \\
& =2 t\left\langle z_{n}-y_{n}, v_{1}\right\rangle+2(1-t)\left\langle z_{n}-y_{n}, v_{2}\right\rangle \\
& \leq\left\|z_{n}\right\|^{2}-\left\|y_{n}\right\|^{2}+\alpha_{n} M,
\end{aligned}
$$

which implies that $C$ is convex. Next, we show that $F(T) \subset C_{n}$ for all $n$. Indeed, for each $p \in F(T)$,

$$
\begin{aligned}
\left\|y_{n}-p\right\|^{2} & =\left\|\alpha_{n} x_{0}-p+\left(1-\alpha_{n}\right)\left(T^{n} z_{n}-p\right)\right\|^{2} \\
& \leq \alpha_{n}\left\|x_{0}-p\right\|^{2}+\left(1-\alpha_{n}\right) k_{n}^{2}\left\|z_{n}-p\right\|^{2} \\
& \leq\left\|x_{n}-p\right\|^{2}-\left\|x_{n}-p\right\|^{2}+\alpha_{n}\left\|x_{0}-p\right\|^{2}+\left(1-\alpha_{n}\right) k_{n}^{2}\left\|z_{n}-p\right\|^{2} \\
& \leq\left\|x_{n}-p\right\|^{2}+\left(\left\|z_{n}-p\right\|^{2}-\left\|x_{n}-p\right\|^{2}\right)+\alpha_{n}\left\|x_{0}-p\right\|^{2} \\
& \leq\left\|x_{n}-p\right\|^{2}+\left(\left\|z_{n}\right\|^{2}-\left\|x_{n}\right\|^{2}+2\left\langle x_{n}-z_{n}, p\right\rangle\right)+\alpha_{n} M .
\end{aligned}
$$

Therefore, $p \in C_{n}$ for each $n \geq 1$, which implies that $F(T) \subset C_{n}$. Next we show that

$$
F(T) \subset Q_{n} \quad \forall n \geq 0
$$

We prove this by induction. For $n=0$, we have $F(T) \subset C=Q_{0}$. Assume that $F(T) \subset Q_{n}$. Since $x_{n+1}$ is the projection of $x_{0}$ onto $C_{n} \cap Q_{n}$, by Lemma 1.2 we have

$$
\left\langle x_{0}-x_{n+1}, x_{n+1}-z\right\rangle \geq 0 \quad \forall z \in C_{n} \cap Q_{n} .
$$

As $F(T) \subset C_{n} \cap Q_{n}$ by the induction assumptions, the last inequality holds, in particular, for all $z \in F(T)$. This together with the definition of $Q_{n+1}$ implies that $F(T) \subset Q_{n+1}$. Hence (2.5) holds for all $n \geq 0$. In order to prove $\lim _{n \rightarrow \infty}\left\|x_{n+1}-x_{n}\right\|=0$, from the definition of $Q_{n}$ we have $x_{n}=P_{Q_{n}} x_{0}$ which together with the fact that $x_{n+1} \in C_{n} \cap Q_{n} \subset Q_{n}$ implies that

$$
\left\|x_{0}-x_{n}\right\| \leq\left\|x_{0}-x_{n+1}\right\|
$$

This shows that the sequence $\left\{x_{n}-x_{0}\right\}$ is nondecreasing. Since $C$ is bounded. We obtain that $\lim _{n \rightarrow \infty}\left\|x_{n}-x_{0}\right\|$ exists. Notice again that $x_{n}=P_{Q_{n}} x_{0}$ and $x_{n+1} \in Q_{n}$ which give 
$6 \quad$ Nonexpansive mapping

$\left\langle x_{n+1}-x_{n}, x_{n}-x_{0}\right\rangle \geq 0$. Therefore, we have

$$
\begin{aligned}
\left\|x_{n+1}-x_{n}\right\|^{2} & =\left\|\left(x_{n+1}-x_{0}\right)-\left(x_{n}-x_{0}\right)\right\|^{2} \\
& \leq\left\|x_{n+1}-x_{0}\right\|^{2}-\left\|x_{n}-x_{0}\right\|^{2}-2\left\langle x_{n+1}-x_{n}, x_{n}-x_{0}\right\rangle \\
& \leq\left\|x_{n+1}-x_{0}\right\|^{2}-\left\|x_{n}-x_{0}\right\|^{2} .
\end{aligned}
$$

It follows that

$$
\lim _{n \rightarrow \infty}\left\|x_{n}-x_{n+1}\right\|=0
$$

On the other hand, It follows from $x_{n+1} \in C_{n}$ that

$$
\left\|y_{n}-x_{n+1}\right\|^{2} \leq\left\|x_{n}-x_{n+1}\right\|^{2}+\left\|z_{n}\right\|^{2}-\left\|x_{n}\right\|^{2}+2\left\langle x_{n}-z_{n}, x_{n+1}\right\rangle+\alpha_{n} M .
$$

It follows from $(2.1)$ and $\lim _{n \rightarrow \infty} \beta_{n}=1$ that

$$
\left\|z_{n}-x_{n}\right\|=\left(1-\beta_{n}\right)\left\|x_{n}-T^{n} x_{n}\right\| \longrightarrow 0
$$

Next, we consider

$$
\begin{aligned}
\left\|z_{n}\right\|^{2} & -\left\|x_{n}\right\|^{2}+2\left\langle x_{n}-z_{n}, x_{n+1}\right\rangle \\
& =\left\|z_{n}\right\|^{2}+\left\|x_{n}\right\|^{2}-2\left\langle z_{n}, x_{n}\right\rangle+2\left\langle x_{n}-z_{n}, x_{n+1}\right\rangle-2\left\|x_{n}\right\|^{2}+2\left\langle z_{n}, x_{n}\right\rangle \\
& =\left\|z_{n}-x_{n}\right\|^{2}+2\left\langle x_{n}-z_{n}, x_{n+1}\right\rangle-2\left\|x_{n}\right\|^{2}+2\left\langle z_{n}, x_{n}\right\rangle \\
& =\left\|z_{n}-x_{n}\right\|^{2}+2\left\langle z_{n}, x_{n}-x_{n+1}\right\rangle-2\left\|x_{n}\right\|^{2}+2\left\langle x_{n}, x_{n+1}\right\rangle .
\end{aligned}
$$

Therefore, it follows from (2.9) and (2.11) that

$$
\left\|z_{n}\right\|^{2}-\left\|x_{n}\right\|^{2}+2\left\langle x_{n}-z_{n}, x_{n+1}\right\rangle \longrightarrow 0
$$

Furthermore, from (2.9), (2.13), and $\lim _{n \rightarrow \infty} \alpha_{n}=0$, we obtain

$$
\lim _{n \rightarrow \infty}\left\|y_{n}-x_{n+1}\right\|=0
$$

On the other hand, we consider

$$
\begin{aligned}
\left\|y_{n}-T^{n} x_{n}\right\| & \leq\left\|y_{n}-T^{n} z_{n}\right\|+\left\|T^{n} z_{n}-T^{n} x_{n}\right\| \\
& \leq \alpha_{n}\left\|x_{0}-T^{n} z_{n}\right\|+k_{n}\left\|z_{n}-x_{n}\right\| \\
& =\alpha_{n}\left\|x_{0}-T^{n} z_{n}\right\|+k_{n}\left(1-\beta_{n}\right)\left\|x_{n}-T^{n} x_{n}\right\| .
\end{aligned}
$$


Therefore, it follows that

$$
\begin{aligned}
\left\|x_{n}-T^{n} x_{n}\right\| \leq & \left\|x_{n}-x_{n+1}\right\|+\left\|x_{n+1}-y_{n}\right\|+\left\|y_{n}-T^{n} x_{n}\right\| \\
\leq & \left\|x_{n}-x_{n+1}\right\|+\left\|x_{n+1}-y_{n}\right\|+\alpha_{n}\left\|x_{0}-T^{n} z_{n}\right\| \\
& +k_{n}\left(1-\beta_{n}\right)\left\|x_{n}-T^{n} x_{n}\right\| .
\end{aligned}
$$

That is,

$$
\left(1-k_{n}\left(1-\beta_{n}\right)\right)\left\|x_{n}-T^{n} x_{n}\right\| \leq\left\|x_{n}-x_{n+1}\right\|+\left\|x_{n+1}-y_{n}\right\|+\alpha_{n}\left\|x_{0}-T^{n} z_{n}\right\| .
$$

It follows from $\lim _{n \rightarrow \infty} \beta_{n}=1, \lim _{n \rightarrow \infty} \alpha_{n}=0,(2.9)$, and (2.14) that

$$
\lim _{n \rightarrow \infty}\left\|x_{n}-T^{n} x_{n}\right\| \longrightarrow 0
$$

Putting $\bar{k}=\sup \left\{k_{n}: n \geq 1\right\}<\infty$, we obtain

$$
\begin{aligned}
\left\|T x_{n}-x_{n}\right\| \leq & \left\|T x_{n}-T^{n+1} x_{n}\right\|+\left\|T^{n+1} x_{n}-T^{n+1} x_{n+1}\right\| \\
& +\left\|T^{n+1} x_{n+1}-x_{n+1}\right\|+\left\|x_{n+1}-x_{n}\right\| \\
\leq & \bar{k}\left\|x_{n}-T^{n} x_{n}\right\|+(1+\bar{k})\left\|x_{n}-x_{n+1}\right\| \\
& +\left\|T^{n+1} x_{n+1}-x_{n+1}\right\|
\end{aligned}
$$

which implies that

$$
\left\|T x_{n}-x_{n}\right\| \longrightarrow 0
$$

Assume that $\left\{x_{n_{i}}\right\}$ is a subsequence of $\left\{x_{n}\right\}$ such that $x_{n_{i}}-\tilde{x}$. By Lemma 1.3 we have $\tilde{x} \in F(T)$. Next we show that $\tilde{x}=P_{F(T)} x_{0}$ and the convergence is strong. Put $\bar{x}=P_{F(T)} x_{0}$ and consider the sequence $\left\{x_{0}-x_{n_{i}}\right\}$. Then we have $x_{0}-x_{n_{i}} \rightarrow x_{0}-\tilde{x}$ and by the weak lower semicontinuity of the norm and by the fact that $\left\|x_{0}-x_{n+1}\right\| \leq\left\|x_{0}-\bar{x}\right\|$ for all $n \geq 0$ which is implied by the fact that $x_{n+1}=P_{C_{n} \cap Q_{n}} x_{0}$, we have

$$
\left\|x_{0}-\bar{x}\right\| \leq\left\|x_{0}-\tilde{x}\right\| \leq \liminf _{i \rightarrow \infty}\left\|x_{0}-x_{n_{i}}\right\| \leq \limsup _{i \rightarrow \infty}\left\|x_{0}-x_{n_{i}}\right\| \leq\left\|x_{0}-\bar{x}\right\| .
$$

This gives

$$
\left\|x_{0}-\bar{x}\right\|=\left\|x_{0}-\tilde{x}\right\|, \quad\left\|x_{0}-x_{n_{i}}\right\| \longrightarrow\left\|x_{0}-\bar{x}\right\| .
$$

It follows that $x_{0}-x_{n_{i}} \rightarrow x_{0}-\bar{x}$; hence, $x_{n_{i}} \rightarrow \bar{x}$. Since $\left\{x_{n_{i}}\right\}$ is an arbitrary subsequence of $\left\{x_{n}\right\}$, we conclude that $x_{n} \rightarrow \bar{x}$. The proof is completed. 
Theorem 2.2. Let $C$ be a nonempty bounded closed convex subset of $H$ and let $S=\{T(s)$ : $0 \leq s<\infty\}$ be an asymptotically nonexpansive semigroup on $C$. Assume that $\left\{\alpha_{n}\right\}_{n=0}^{\infty}$ and $\left\{\beta_{n}\right\}_{n=0}^{\infty}$ are sequences in $(0,1)$ such that $\lim _{n \rightarrow \infty} \alpha_{n}=0$ and $\lim _{n \rightarrow \infty} \beta_{n}=1 .\left\{t_{n}\right\}$ is a positive real divergent sequence and $M$ is an appropriate constant such that $M \geq\left\|x_{0}-v\right\|$ for all $v \in C$. Define a sequence $\left\{x_{n}\right\}$ in $C$ by the following algorithm:

$$
\begin{gathered}
x_{0} \in C \quad \text { chosen arbitrarily, } \\
z_{n}=\beta_{n} x_{n}+\left(1-\beta_{n}\right) \frac{1}{t_{n}} \int_{0}^{t_{n}} T(s) x_{n} d s, \\
y_{n}=\alpha_{n} x_{0}+\left(1-\alpha_{n}\right) \frac{1}{t_{n}} \int_{0}^{t_{n}} T(s) z_{n} d s, \\
C_{n}=\left\{v \in C:\left\|y_{n}-v\right\|^{2} \leq \alpha_{n}\left\|x_{n}-v\right\|^{2}+\left\|z_{n}\right\|^{2}-\left\|x_{n}\right\|^{2}+2\left\langle x_{n}-z_{n}, v\right\rangle+\alpha_{n} M\right\}, \\
Q_{n}=\left\{v \in C:\left\langle x_{0}-x_{n}, x_{n}-z\right\rangle \geq 0\right\}, \\
x_{n+1}=P_{C_{n} \cap Q_{n}} x_{0} .
\end{gathered}
$$

Then $\left\{x_{n}\right\}$ converges to $P_{F(S)} x_{0}$, provided $\left(\left(1 / t_{n}\right) \int_{0}^{t_{n}} L_{s} d t\right)^{2}\left(1-\alpha_{n}\right)-1 \leq 0$.

Proof. We only conclude the difference. First we show $F(S) \subset C_{n}$. It follows from $C$ is bounded, we obtain that $F(S) \neq \varnothing$ (see [12]). Taking $p \in F(S)$, we have

$$
\begin{aligned}
\left\|y_{n}-p\right\|^{2} & \leq \alpha_{n}\left\|x_{0}-p\right\|^{2}+\left(1-\alpha_{n}\right)\left\|\frac{1}{t_{n}} \int_{0}^{t_{n}} T(s) z_{n} d s-p\right\|^{2} \\
& \leq \alpha_{n}\left\|x_{0}-p\right\|^{2}+\left(1-\alpha_{n}\right)\left(\frac{1}{t_{n}} \int_{0}^{t_{n}}\left\|T(s) z_{n}-p\right\| d s\right)^{2} \\
& \leq \alpha_{n}\left\|x_{0}-p\right\|^{2}+\left(1-\alpha_{n}\right)\left(\frac{1}{t_{n}} \int_{0}^{t_{n}} L_{s} d s\right)^{2}\left\|z_{n}-p\right\|^{2} \\
& =\left\|x_{n}-p\right\|^{2}+\left(\left\|z_{n}-p\right\|^{2}-\left\|x_{n}-p\right\|^{2}\right)+\alpha_{n}\left\|x_{0}-p\right\|^{2} \\
& \leq\left\|x_{n}-p\right\|^{2}+\left(\left\|z_{n}\right\|^{2}-\left\|x_{n}\right\|^{2}+2\left\langle x_{n}-z_{n}, p\right\rangle\right)+\alpha_{n} M .
\end{aligned}
$$

It follows that $F(S) \subset C_{n}$ for each $n \geq 0$. From the proof of Theorem 2.1 we have the sequence $\left\{x_{n}\right\}$ is well defined and $F(S) \subset C_{n} \cap Q_{n}$ for each $n \geq 0$. Similarly to the argument of Theorem 2.1 and noticing $q=P_{F(S)} x_{0}$, we have $\left\|x_{n+1}-x_{0}\right\| \leq\left\|q-x_{0}\right\|$ for each $n \geq 0$ and $\left\|x_{n+1}-x_{n}\right\| \rightarrow 0$. Next, we assume that a subsequence $\left\{x_{n_{i}}\right\}$ of $\left\{x_{n}\right\}$ converges weakly 
to $q$. It follows that

$$
\begin{aligned}
\left\|T(s) x_{n}-x_{n}\right\| \leq & \left\|T(s) x_{n}-T(s)\left(\frac{1}{t_{n}} \int_{0}^{t_{n}} T(s) x_{n} d s\right)\right\| \\
& +\left\|T(s)\left(\frac{1}{t_{n}} \int_{0}^{t_{n}} T(s) x_{n} d s\right)-\frac{1}{t_{n}} \int_{0}^{t_{n}} T(s) x_{n} d s\right\| \\
& +\left\|\frac{1}{t_{n}} \int_{0}^{t_{n}} T(s) x_{n} d s-x_{n}\right\| \\
\leq & 2\left\|\frac{1}{t_{n}} \int_{0}^{t_{n}} T(s) x_{n} d s-x_{n}\right\| \\
& +\left\|T(s)\left(\frac{1}{t_{n}} \int_{0}^{t_{n}} T(s) x_{n} d s\right)-\frac{1}{t_{n}} \int_{0}^{t_{n}} T(s) x_{n} d s\right\|,
\end{aligned}
$$

for each $n \geq 0$. It follows from (2.23) that

$$
\left\|y_{n}-\frac{1}{t_{n}} \int_{0}^{t_{n}} T(s) z_{n} d s\right\| \leq \alpha_{n}\left\|x_{0}-\frac{1}{t_{n}} \int_{0}^{t_{n}} T(s) z_{n} d s\right\|
$$

Therefore, we obtain

$$
\left\|y_{n}-\frac{1}{t_{n}} \int_{0}^{t_{n}} T(s) z_{n} d s\right\| \longrightarrow 0 .
$$

Next, we consider the first term on the right-hand side of (2.25)

$$
\left\|\frac{1}{t_{n}} \int_{0}^{t_{n}} T(s) x_{n} d s-x_{n}\right\| \leq\left\|x_{n}-x_{n+1}\right\|+\left\|x_{n+1}-y_{n}\right\|+\left\|y_{n}-\frac{1}{t_{n}} \int_{0}^{t_{n}} T(s) x_{n} d s\right\| .
$$

Since $x_{n+1} \in C_{n}$, we have

$$
\left\|y_{n}-x_{n+1}\right\|^{2} \leq \alpha_{n}\left\|x_{n}-x_{n+1}\right\|^{2}+\left\|z_{n}\right\|^{2}-\left\|x_{n}\right\|^{2}+2\left\langle x_{n}-z_{n}, x_{n+1}\right\rangle+\alpha_{n} M .
$$

Similar to the proof of Theorem 2.1, we have

$$
\lim _{n \rightarrow \infty}\left\|y_{n}-x_{n+1}\right\|=0,
$$

and hence

$$
\begin{aligned}
\| y_{n}- & \frac{1}{t_{n}} \int_{0}^{t_{n}} T(s) x_{n} d s \| \\
& \leq\left\|y_{n}-\frac{1}{t_{n}} \int_{0}^{t_{n}} T(s) z_{n} d s\right\|+\left\|\frac{1}{t_{n}} \int_{0}^{t_{n}} T(s) z_{n} d s-\frac{1}{t_{n}} \int_{0}^{t_{n}} T(s) x_{n} d s\right\| \\
& \leq\left\|y_{n}-\frac{1}{t_{n}} \int_{0}^{t_{n}} T(s) z_{n} d s\right\|+\frac{1}{t_{n}} \int_{0}^{t_{n}}\left\|T(s) z_{n}-T(s) x_{n}\right\| d s \\
& \leq\left\|y_{n}-\frac{1}{t_{n}} \int_{0}^{t_{n}} T(s) z_{n} d s\right\|+\left(\frac{1}{t_{n}} \int_{0}^{t_{n}} L_{s} d s\right)\left\|z_{n}-x_{n}\right\|^{2} .
\end{aligned}
$$


Since $\lim _{n \rightarrow \infty} \beta_{n}=1$, we have

$$
\left\|z_{n}-x_{n}\right\|=\left(1-\beta_{n}\right)\left\|x_{n}-\frac{1}{t_{n}} \int_{0}^{t_{n}} T(s) x_{n} d s\right\| \longrightarrow 0 .
$$

It follows from (2.27) and (2.32) that

$$
\left\|y_{n}-\frac{1}{t_{n}} \int_{0}^{t_{n}} T(s) x_{n} d s\right\| \longrightarrow 0
$$

It follows from (2.30) and (2.33) that

$$
\left\|x_{n}-\frac{1}{t_{n}} \int_{0}^{t_{n}} T(s) x_{n} d s\right\| \longrightarrow 0 .
$$

On the other hand, by using Lemma 1.4 we obtain

$$
\limsup _{s \rightarrow \infty} \limsup _{n \rightarrow \infty}\left\|T(s)\left(\frac{1}{t_{n}} \int_{0}^{t_{n}} T(s) x_{n} d s\right)-\frac{1}{t_{n}} \int_{0}^{t_{n}} T(s) x_{n} d s\right\|=0 .
$$

It follows from (2.34) and (2.35) that

$$
\underset{s \rightarrow \infty}{\limsup } \limsup _{n \rightarrow \infty}\left\|T(s) x_{n}-x_{n}\right\|=0 .
$$

Assume that a $\left\{x_{n_{i}}\right\}$ is a subsequence of $\left\{x_{n}\right\}$ such that $\left\{x_{n_{i}}\right\} \rightarrow q \in C$, then $q \in F(S)$ (by Lemma 1.5). Next we show that $q=\Pi_{F(S)} x_{0}$ and the convergence is strong. Put $q^{\prime}=$ $\Pi_{F(S)} x_{0}$, from $x_{n+1}=\Pi_{C_{n} \cap Q_{n}} x_{0}$ and $q^{\prime} \in F(S) \subset C_{n} \cap Q_{n}$, we have $\left\|x_{n+1}-x_{0}\right\| \leq\left\|q^{\prime}-x_{0}\right\|$. On the other hand, from weakly lower semicontinuity of the norm, we obtain

$$
\begin{aligned}
\left\|q^{\prime}-x_{0}\right\| & \leq\left\|x_{0}-q\right\| \leq \liminf _{i \rightarrow \infty}\left\|x_{0}-x_{n_{i}}\right\| \\
& \leq \limsup _{i \rightarrow \infty}\left\|x_{0}-x_{n_{i}}\right\| \\
& \leq\left\|q-x_{0}\right\| .
\end{aligned}
$$

It follows from definition of $\Pi_{F(S)} x_{0}$ that we obtain $q=\Pi_{F(S)} x_{0}$ and hence

$$
\left\|q^{\prime}-x_{0}\right\|=\left\|q-x_{0}\right\|
$$

It follows that $x_{n_{i}} \rightarrow q^{\prime}$. Since $\left\{x_{n_{i}}\right\}$ is an arbitrarily weakly convergent sequence of $\left\{x_{n}\right\}$, we can conclude that $\left\{x_{n}\right\}$ converges strongly to one point of $\Pi_{F(S)} x_{0}$. This completes the proof.

\section{References}

[1] A. Genel and J. Lindenstrauss, An example concerning fixed points, Israel Journal of Mathematics 22 (1975), no. 1, 81-86.

[2] K. Goebel and W. A. Kirk, A fixed point theorem for asymptotically nonexpansive mappings, Proceedings of the American Mathematical Society 35 (1972), no. 1, 171-174. 
[3] B. Halpern, Fixed points of nonexpanding maps, Bulletin of the American Mathematical Society 73 (1967), 957-961.

[4] T.-H. Kim and H.-K. Xu, Strong convergence of modified Mann iterations for asymptotically nonexpansive mappings and semigroups, Nonlinear Analysis 64 (2006), no. 5, 1140-1152.

[5] P.-K. Lin, K.-K. Tan, and H.-K. Xu, Demiclosedness principle and asymptotic behavior for asymptotically nonexpansive mappings, Nonlinear Analysis 24 (1995), no. 6, 929-946.

[6] P.-L. Lions, Approximation de points fixes de contractions, Comptes Rendus de l'Académie des Sciences de Paris, Série. A-B 284 (1977), no. 21, A1357-A1359.

[7] C. Martinez-Yanes and H.-K. Xu, Strong convergence of the CQ method for fixed point iteration processes, Nonlinear Analysis 64 (2006), no. 11, 2400-2411.

[8] K. Nakajo and W. Takahashi, Strong convergence theorems for nonexpansive mappings and nonexpansive semigroups, Journal of Mathematical Analysis and Applications 279 (2003), no. 2, 372379.

[9] S. Reich, Weak convergence theorems for nonexpansive mappings in Banach spaces, Journal of Mathematical Analysis and Applications 67 (1979), no. 2, 274-276.

[10] Strong convergence theorems for resolvents of accretive operators in Banach spaces, Journal of Mathematical Analysis and Applications 75 (1980), no. 1, 287-292.

[11] Approximating fixed points of nonexpansive mappings, Panamerican Mathematical Journal 4 (1994), no. 2, 23-28.

[12] K.-K. Tan and H.-K. Xu, Fixed point theorems for Lipschitzian semigroups in Banach spaces, Nonlinear Analysis 20 (1993), no. 4, 395-404.

[13] R. Wittmann, Approximation of fixed points of nonexpansive mappings, Archiv der Mathematik 58 (1992), no. 5, 486-491.

[14] D. Youla, Mathematical theory of image restoration by the method of convex projections, Image Recovery Theory and Application (H. Stark, ed.), Academic Press, Florida, 1987, pp. 29-77.

[15] _ On deterministic convergence of iteration of relaxed projection operators, Journal of Visual Communication and Image Representation 1 (1990), no. 1, 12-20.

Yongfu Su: Department of Mathematics, Tianjin Polytechnic University, Tianjin 300160, China E-mail address: suyongfu@tjpu.edu.cn

Xiaolong Qin: Department of Mathematics, Tianjin Polytechnic University, Tianjin 300160, China E-mail address: qxlxajh@163.com 